\title{
A INFORMACIÓN GRAMATICAL NOS DICIONARIOS
}

\author{
Xosé-Álvaro Porto Dapena
}

Universidade da Coruña

\section{O. INTRODUCIÓN}

Cando nos preguntamos pola información gramatical nos dicionarios, estamos a partir en realidade da existencia dunha dicotomía -a de gramática / dicionario-, na que certamente cada día se cre menos, aínda que, por outro lado, veña sendo mantida tradicionalmente mesmo dende moito antes de que Saussure fundase a lingüística sobre as súas famosas antinomías. Estou seguro de que a inmensa maioría dos que aquí nos atopamos seguimos pensando que posuír unha lingua non consiste basicamente noutra cousa que, por unha banda, en coñecer o seu vocabulario e, por outra, en dominar as regras gramaticais que nos permiten xerar ou producir, a partir daquel, un indefinido número de enunciados. Pero non é menos certo, ao mesmo tempo, que todos estamos absolutamente convencidos de que en materia de linguaxe -e, polo tanto, tamén na lingüística-non hai compartimentos estancos, de maneira que nunca se poden facer delimitacións exactas e, conseguintemente, os límites que intentemos establecer serán sempre imprecisos e necesariamente difusos.

No que aos terreos da Lexicografía e da Gramática se refire, esta indefinición púxoa recentemente moi ben de manifesto Ignacio Bosque (2004: LXXIX e ss.) na introdución do seu REDES, dicionario dedicado, como é sabido, ao aspecto combinatorio do léxico, por certo nunca tratado anteriormente en ningunha lingua. Segundo observa, cando informaba das particulares características da súa obra, aínda en elaboración, aos colegas, había discrepancias entre eles no sentido de que, se eran gramáticos, lle dicían que o que estaba a facer era lexicografía, mentres que, tratándose de lexicógrafos, se inclinaban a pensar que a súa investigación correspondía, pola contra, ao ámbito do gramatical. E certamente nin el mesmo -que, segundo confesa, non é lexicógrafo, senón gramático- parece estar moi 
seguro de que a súa obra, malia o seu título, sexa un verdadeiro dicionario, cousa que eu -que si son lexicógrafo-xamais puxen en dúbida, nin sequera antes de ser publicada, nas miñas conversas co propio Bosque.

Para empezar, sinalemos que opoñer Gramática e Dicionario implica ante todo ter unha idea clara e á vez particular -aínda que só sexa teoricamente- dos respectivos dominios destas dúas disciplinas, dominios que aínda non foron fixados dun modo unánime. Sen entrar na dificultade -posta de manifesto hai algúns anos por Alvar Ezquerra (1993: 59 e ss.)-á hora de definir o concepto de 'dicionario', abonde con fixarnos na variedade de concepcións sobre o verdadeiro contido e extensión da Gramática, concepcións que, por certo, non sempre permiten manter a súa oposición fronte ao Dicionario. Pensemos, se non, no caso dos xenerativistas cando a interpretan no seu sentido máis amplo, equivalente a Lingüistica, e segundo o cal o Dicionario ou Lexicón non viría a ser máis que unha das súas partes ou compoñentes.

É evidente que, se nos preguntamos pola presenza de información gramatical nos dicionarios, é porque estamos a entender a Gramática no seu sentido máis tradicional e xeneralizado, é dicir, como a suma de Morfoloxía e Sintaxe, entendida a primeira, grosso modo, como "estudo da forma das palabras" e a segunda como "estudo da combinatoria destas para formar unidades sintagmáticas de orde máis complexa, isto é, frases ou oracións". Porque neste sentido, efectivamente, os dicionarios -aínda sen saír dos máis comúns e correntes, isto é, os de carácter xeral, alfabético e sobre todo didáctico- abundan en informacións de tipo morfolóxico e sintáctico, mesmo máis alá do que, ás veces, poidan mostrar as puras aparencias. E sendo isto así, un dicionario típico, isto é, de carácter semasiolóxico, non consiste -contra o que talvez tende a pensarse- nun puro estudo semántico do léxico, exclusivamente encamiñado a informar dos significados ou acepcións das palabras, senón que, como non podería ser doutro xeito, nos informa ademais doutros moitos aspectos, entre os que cabe destacar, por ser o tema deste traballo, o morfolóxico e, sobre todo, o sintáctico.

\section{ALGUNHAS CUESTIÓNS PREVIAS}

\subsection{Contido do dicionario}

O Dicionario, segundo iso, preséntasenos como un estudo híbrido, isto é, a cabalo entre o estritamente lexical, que constituiría o seu primordial 
e xenuíno ámbito, e o gramatical, chegando a abranguer mesmo outros moitos campos que nalgúns casos superan o terreo estritamente lingüistico, para incluír tamén o que non é máis que saber enciclopédico. Non fai falta insistir en que, efectivamente, nun dicionario podemos atopar, por exemplo, información etimolóxica, terminolóxica, pragmática, sociolingüistica, dialectal, fonético-fonolóxica, ortográfica e un longo etcétera, dependendo -claro está- do tipo específico de dicionario.

Pero volvendo á cuestión da información gramatical, aínda que de feito non se pode negar a existencia de certo solapamento entre Dicionario e Gramática, de sorte que nun e noutra atopamos ás veces estudadas as mesmas cuestións (pensemos, por exemplo, no tratamento das preposicións e, en xeral, das chamadas palabras gramaticais), non é menos certo que, en non poucas ocasións, se lle nega lexitimidade ao Dicionario para ocuparse de cuestións de natureza morfolóxica ou sintáctica, porque -penso que erroneamente- se consideran todas elas patrimonio exclusivo da Gramática. A mesma denominación que ás veces utilizamos -eu o primeiro (véxase, por exemplo, Porto Dapena 2002a: 64)- de dicionarios gramaticais para referirnos a aqueles cuxas entradas se elixen atendendo precisamente a certas peculiaridades morfosintácticas, pon ben ás claras a vixencia de semellante opinión.

É, non obstante, un erro negar que, por exemplo, un dicionario non debe dar conta de que un verbo ha de construírse cun determinado tipo de complemento, de que un adxectivo pode xuntarse soamente a certos substantivos ou de que unha determinada palabra pode funcionar como adverbio e preposición ou ofrece, por outro lado, algunha particularidade na súa conformación morfonolóxica. E é un erro porque tales cuestións, lonxe de pertenceren á Gramática -tal como a entendemos normalmente-, corresponden só e exclusivamente ao Dicionario.

E chegados a este punto, véxome na necesidade de observar que Morfoloxía e Sintaxe non son -contra o que comunmente tende a pensarsedisciplinas exclusivamente gramaticais, senón tamén léxicas, de sorte que entre elas, por unha parte, e entre Gramática e Dicionario, por outra, se dá unha relación de cruzamento, tal como se pode esquematizar no seguinte gráfico: 


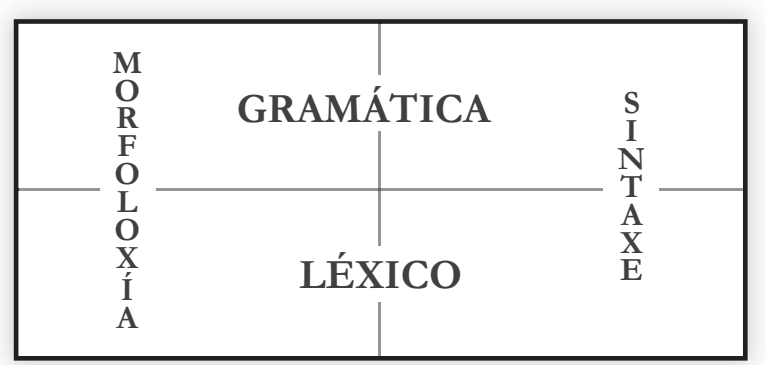

Aínda que -insisto- a delimitación entre os membros de cada un destes dous pares de disciplinas sexa na práctica relativamente difusa, non cabe a máis mínima dúbida de que así como na Gramática existen unha morfoloxía e unha sintaxe, tamén no estudo do léxico -e por ende na Lexicografía- haberá que facer a mesma distinción. Hai que falar, como se fai con frecuencia, dunha morfoloxía léxica xunto a unha morfoloxía gramatical, preocupada esta última fundamentalmente polos aspectos flexivos; pero tamén dunha sintaxe léxica, referida ao nivel máis concreto da palabra, fronte a unha sintaxe gramatical, enfocada máis ben ao estudo da oración e as súas partes ou funcións.

\subsection{Delimitando o noso obxecto de estudo}

Aínda que resulte un pouco contraditorio co que acabo de observar, cando se me suxeriu que me ocupase da información gramatical nos dicionarios, entendín inmediatamente que o que se me estaba a propoñer era que tratase fundamentalmente de cuestións de morfoloxía e, sobre todo, de sintaxe léxicas rexistradas nos dicionarios xerais e comúns. Por iso é nelas -moi especialmente nas sintácticas- no que vou centrar o obxecto da miña exposición. Non hai que perder de vista, non obstante, que van quedar fóra outros aspectos -neste caso máis estritamente gramaticais e sen dúbida interesantes-, como pode ser, por exemplo, o tratamento nos mesmos dicionarios de palabras gramaticais, de cuestións relacionadas coa flexión e categorización das palabras ou, en fin, o estudo da terminoloxía gramatical e con el da propia Gramática.

Respecto a isto último, xa dicía Gili Gaya (1945) que un dicionario non debe ser unha gramática estruturada en artigos dispostos por orde alfabética, aínda cando é aceptable que, sobre todo tratándose de dicionarios de tipo escolar, se empregue certa manga ancha neste aspecto, incluíndo, entre outras cousas, explicacións e informacións de tipo gramatical, como poden ser paradigmas flexionais, formas irregulares e mesmo algunhas regras sintácticas elementais. Dende logo, todos nos temos beneficiado algunha vez da presenza destas cuestións gramaticais nos nosos peque- 
nos dicionarios bilingües cando eramos estudantes. Pero non hai que acudir exclusivamente aos dicionarios escolares para constatar este feito, pois tamén os dicionarios comúns e correntes de tipo máis ou menos descritivo e normativo - pensemos, para o español, no DRAE ou no DUE de María Moliner- tenden a incluír así mesmo este tipo de información en atención a que están destinados a un público non particularmente versado en materia gramatical.

En calquera das dúas estruturas que caracterizan un dicionario pode detectarse a información morfosintáctica. En primeiro lugar, na macroestrutura, isto é, atendendo ao lemario ou conxunto de entradas, e en segundo termo, na microestrutura ou interior do artigo lexicográfico. No primeiro caso cabe aínda referirnos a dous aspectos: o que atende aos tipos de léxico rexistrado, ao incluír, entre outras cousas, palabras ou morfemas gramaticais así como elementos morfolóxicos -por exemplo, prefixos e sufixos derivativos-, e, por outra banda, o que se refire máis ben á forma da entrada, a cal, ademais de informar sobre a súa propia ortografía, pode facelo así mesmo sobre as súas particularidades morfolóxicas, e ata ás veces fonético-fonolóxicas.

Dende logo todos os dicionarios de tipo xeral rexistran as chamadas palabras gramaticais, isto é, pronomes, preposicións e conxuncións, de modo que aquí atopamos o primeiro solapamento entre Gramática -que é máis propiamente a que debe estudar estes elementos- e o Dicionario, o cal, por outro lado, cando é de tipo xeral, non se limita a recoller as unidades léxicas, senón todo tipo de vocábulos indo mesmo máis alá destes: por exemplo, a rexistrar así mesmo certos afixos ou, sen ir máis lonxe, as letras do abecedario (véxase a este respecto Porto Dapena 2000-2001) e ata ás veces elementos que non pertencen propiamente á lingua, como é o caso do DUE de María Moliner cando recolle mesmo certos clics (jchsss!, $\mathrm{mmm}$, etc.).

Pero falando de elementos de tipo gramatical incluídos na nomenclatura do Dicionario, cabe aínda -seguindo unha feliz distinción de Eugenio Coseriu (1977: 107-109) entre linguaxe primaria e metalinguaxe-separar entre entradas gramaticais, as representadas por pronomes, preposicións, formas irregulares, etc., que pertencen, obviamente, á linguaxe primaria, e, por outro lado, entradas de gramática, isto é, terminoloxía gramatical, pertencente ao léxico especializado da Gramática -ou, máis ben, da Lingüística-, estudado ás veces enciclopedicamente non só, por suposto, nos dicionarios e vocabularios especializados, senón mesmo ás veces -se ben iso non se xustifique doadamente- nos dicionarios xerais e comúns. Exemplificando co mesmo DUE de María Moliner, os artigos que esta au- 
tora chama "de desarrollo gramatical" corresponden precisamente a este último tipo de entradas.

Aínda se atendemos á lematización ou forma en que aparecen rexistradas as entradas no Dicionario, este pode ofrecer de feito información gramatical. Se, ante todo, incluímos dentro desta a de tipo ortográfico, ¿quen non usou algunha vez o dicionario para descubrir, en caso de dúbida, como se escribe unha palabra? Pero, referíndonos máis especificamente ao aspecto morfolóxico, non é infrecuente no enunciado das entradas que, ao lado do lema, isto é, a forma básica que se toma en conta para a orde alfabética, aparezan outras formas ou ben de tipo flexional (por exemplo, a forma feminina xunto á masculina nos artigos de adxectivos e de certos substantivos) ou ben variantes de tipo morfonolóxico, dando así lugar a enunciados polimórficos.

A pesar de todo isto, a maior -e talvez máis importante-información tanto morfolóxica como, sobre todo, sintáctica nos dicionarios vén dada na microestrutura, xa sexa directamente, isto é, mediante explicacións ad hoc ou por medio da correspondente marcación gramatical, para indicar neste caso, en abreviatura, a categoría ou subcategoría (por exemplo, adxectivo, transitivo, masculino, plural), xa sexa indirectamente, como algo que se desprende doadamente das propias definicións ou dos contextos de que estas forman parte. Así, non é infrecuente nos dicionarios correntes sinalar o tipo de conxugación propia dos verbos irregulares ou indicar as peculiaridades prosódicas e mesmo ás veces de pronuncia cando se trata dunha palabra - polo regular un empréstito- cuxa ortografía non se adapta ás regras xerais de equivalencia entre grafía e pronuncia. Moitos dicionarios sinalan tamén certas posibilidades de construción; por exemplo, cando se di dun verbo que tamén se usa como pronominal ou que rexe unha determinada preposición, que vai acompañado dun complemento especial, etc.

É xeralmente neste último punto de vista no que os dicionarios comúns e correntes adoitan ser menos explícitos, confiando na maior parte dos casos na competencia e intuición lingüística dos usuarios, que se ven obrigados a descubriren indirectamente as peculiaridades sintácticas ou combinatorias da palabra en cada unha das súas acepcións. Precisamente é neste último tipo de información -ao tratarse sen dúbida do aspecto menos evidente e coñecido e, por iso, máis interesante- no que vou centrar o resto da miña exposición, pois o tema deste traballo é tan amplo que nos sería imposible abranguelo aquí en todos os aspectos que acabo de sinalar moi esquematicamente. 
Así pois, vou referirme concretamente á información sintáctica contida-case sempre implicitamente-nas definicións lexicográficas, ou nos contextos de que estas forman parte dentro das respectivas acepcións. Os exemplos que vou utilizar corresponden todos eles a dicionarios do español, concretamente ao DRAE, ao DUE e ao DEA de Manuel Seco, Olimpia Andrés e Gabino Ramos, por ser a lexicografía española o ámbito no que máis traballei e, polo tanto, mellor me movo.

\section{A INFORMACIÓN GRAMATICAL NA MACROESTRUCTURA}

De acordo, pois, co esquema que acabo de trazar, voume fixar antes de nada na información gramatical contida na macroestrutura dos dicionarios. E neste punto, atendendo en primeiro lugar ao tipo de léxico estudado, cabe sinalar, como vimos antes, a presenza de, por unha parte, palabras ou elementos de significación exclusivamente gramatical, como as partículas e os pronomes, xunto a voces pertencentes ao que poderiamos chamar metaléxico, é dicir, referentes a realidades gramaticais ou lingüísticas en xeral. Pero así mesmo, independentemente do significado ou referencia das entradas, o modo como estas aparecen rexistradas no dicionario pode nalgunha medida informar acerca dalgunha ou dalgunhas das súas peculiaridades gramaticais.

\subsection{Con atención ao tipo de léxico rexistrado}

Non é este, dende logo, o momento de entrar na discusión acerca do nivel ou niveis de unidades lingüísticas que deben ou non formar parte da nomenclatura dun dicionario. Todos estamos de acordo en que as entradas están constituídas basicamente por palabras; palabras ortográficas, claro está, posto que nos estamos a referir a unha obra de carácter escrito. Iso non obsta, sen embargo, para que, á súa vez, formen parte da nomenclatura elementos menores que a palabra, como é o caso de certos sufixos ou prefixos utilizados na formación de palabras, e mesmo outros -como é o caso das letras do abecedario ou dos clics- que non son nin sequera unidades lingüísticas propiamente falando.

A presenza na nomenclatura dos dicionarios das chamadas palabras gramaticais constitúe sen dúbida o máis claro expoñente de interferencia entre gramática e dicionario. Realmente o punto de vista adoptado na descrición das conxuncións e preposicións, por exemplo, non varía substancialmente dun dicionario a un tratado gramatical, a non ser talvez 
no carácter polo xeral máis minucioso daquel: comparemos, sen ir máis lonxe, o tratamento, de apenas dúas páxinas, que se dá á preposición entre na Gramática descriptiva de la lengua española dirixida por Bosque e Demonte (De Bruyne 1999: 674-676) co correspondente artigo, redactado por min mesmo, do $D C R$, que ocupa máis de vinte páxinas a dobre columna. As diferenzas entre dicionarios e gramáticas son talvez maiores no que se refire ao tratamento dos pronomes, debido, entre outras razóns, á necesidade de ter que adaptarse naqueles á estruturación alfabética, o que fai que formas dun mesmo paradigma gramatical -como poden ser, por exemplo, en galego, eu, me ou comigo, ou as correspondentes formas yo, me, conmigo do español- aparezan espalladas en lugares moi distintos da macroestrutura dun dicionario.

O tratamento, por certo, que na simple nomenclatura reciben os pronomes ou o artigo, xunto cos hoxe chamados determinantes, pode ser índice das bases teóricas que, con respecto á concepción do pronome, subxacen no propio dicionario. Así, por exemplo, pode ser significativo que, como acontece no DGILE, se rexistren como entradas independentes os demostrativos en función adxectiva e en función substantiva, o que significa que o autor ou autores do dicionario opoñen -como, por outra parte, se veu facendo frecuentemente- os adxectivos demostrativos aos seus correspondentes pronomes, reducidos á función substantiva. De todos os xeitos, como estudei nun artigo sobre o tema (Porto Dapena 2003-2004), os dicionarios mostran unha gran vacilación á hora de rexistrar na súa nomenclatura as formas pronominais, que tenden, como acabo de observar, á dispersión, ao figurar cada forma na súa correspondente posición alfabética. Por iso, quizais, pode dicirse que os pronomes en xeral aparecen, dende logo, mellor tratados nas gramáticas que nos dicionarios.

Algo parecido ao que acabo de dicir dos pronomes se pode afirmar de palabras, sobre todo verbos, con flexión irregular. Neste caso, efectivamente, non será imposible, sobre todo en dicionarios de aprendizaxe, rexistrar como entradas independentes as formas irregulares, remitindo -claro está- en cada unha delas á forma baixo a cal se describe o correspondente vocábulo e onde se informa, entre outras cousas, das correspondentes irregularidades.

Evidentemente, este modo de proceder explícase sobre todo nos chamados dicionarios pedagóxicos ou de aprendizaxe, posto que van destinados a un público cun baixo nivel de coñecementos en materia gramatical. A mesma explicación pode valer, por certo, para xustificar a presenza na nomenclatura dos dicionarios xerais da terminoloxía gramatical ou lingüística, isto é, do metaléxico utilizado na descrición das linguas, cir- 
cunstancia que se aproveita ás veces para ofrecer na correspondente microestrutura todo un estudo de tipo gramatical, entrando así o Dicionario no que xa habería que considerar saber enciclopédico. Considérese a este propósito, por exemplo, o longo artigo, de máis de corenta páxinas, que a propósito da palabra verbo aparece na primeira edición do DUE de María Moliner, o cal constitúe un amplo e detallado capítulo digno de figurar nun tratado de gramática descritiva.

De todos os xeitos, habemos de coincidir con Gili Gaya en que un dicionario, como xa queda sinalado, non debe ser nunca unha gramática estruturada en capítulos dispostos por orde alfabética, que é realmente o que María Moliner fixo cos artigos "de desarrollo gramatical" e que, precisamente por esa razón, os encargados de preparar a segunda edición do $D U E$, eliminaron da nomenclatura, pasándoos a formar un longo apéndice ao final da obra. É inevitable, con todo, que un dicionario común trate o léxico metalingüistico, aínda que, evidentemente, sen chegar ao grao de especialización dun dicionario de lingüística ou sobre terminoloxía gramatical, nin, por suposto -simplemente porque cadra de camiño-, tomar como pretexto ese vocabulario para desenvolver toda unha teoría lingüística ou un estudo detallado da gramática da lingua en cuestión.

Isto último suporía unha confusión -por certo bastante frecuente nos dicionarios comúns-entre o lingüístico e a realidade (aínda que neste caso esteamos a falar á vez dunha realidade lingüística), pois unha cousa, loxicamente, será definir a palabra verbo, que é o que atinxe ao dicionario, e outra ocuparse -como fai María Moliner-da realidade chamada verbo. Ás veces a confusión é tan forte que se chegan a incluír na nomenclatura dos dicionarios elementos que, aínda sendo realidades lingüísticas, non constitúen verdadeiras unidades léxicas, como é o caso, por exemplo, das letras, segundo puxen de manifesto hai algún tempo nun artigo sobre o tema (Porto Dapena 2000-2001). Realmente unha entrada como B, por exemplo, non é unha palabra (fronte ao substantivo be), senón a letra mesma, a cal, malia ser unha realidade gráfica -e, polo tanto, lingüística-, non debería figurar como entrada en ningún dicionario e só, en todo caso, nunha enciclopedia. Cando, efectivamente, o DRAE nos define

\footnotetext{
b 1. $f$. Segunda letra del abecedario español y del orden latino internacional, que representa un fonema consonántico labial y sonoro. Su nombre es be, be alta o be larga.
}

non nos está a dar o significado dunha palabra $b$ inexistente, senón que nos está a caracterizar a letra mesma, o signo ortográfico; por iso non ten ningún sentido a marcación $f$. (feminino) que fai desta entrada. 
Situación moi distinta é a correspondente aos afixos derivativos, pois, malia non ser palabras, constitúen unidades lingüísticas cun significado e unha evidente potencialidade combinatoria para constituír novos vocábulos ou facer posible a análise doutros xa existentes. De aí que os dicionarios sexan cada día máis proclives a aceptar estes elementos morfolóxicos na súa nomenclatura, facendo así innecesario o rexistro de, por exemplo, aumentativos e diminutivos nos substantivos, ou superlativos nos adxectivos, que tanto inflaron noutro tempo a macroestrutura do $D R A E$. En realidade estas formas -así como outros tipos de derivados (por exemplo, os deverbais) - deberían ser tratados na microestrutura, quero dicir, nos artigos correspondentes ás palabras de que derivan, a non ser, loxicamente, cando presentan significados non previsibles, isto é, non derivables dos seus elementos morfolóxicos compoñentes.

\subsection{Con atención á lematización ou forma das entradas}

Pero, como xa queda dito, a información gramatical na macroestrutura non só vén dada polo tipo de entradas que a constitúen, senón tamén pola forma en que estas aparecen rexistradas no dicionario. É dicir, a lematización representa sen dúbida -sexa directa ou indirectamente- un aspecto importante para determinar algunhas características gramaticais das palabras tomadas como entradas. Concretamente, as relacionadas en primeiro lugar coa súa ortografía e pronuncia, e, en segundo termo, as que atinxen, por exemplo, ás súas características flexionais, morfonolóxicas ou gráficas.

Máis arriba, en efecto, xa me referín ao feito -en absoluto infrecuente- de que os dicionarios comúns son consultados coa especifica finalidade de descubrir a ortografía dun vocábulo concreto. Trátase -claro estádun tipo de información indirecta, por canto que a entrada, ao vir dada na súa representación gráfica, fai supoñer que tal representación ha de ser a correcta. Nalgúns dicionarios, non obstante, ao lado do lema -isto é, a forma do enunciado do artigo sometida á orde alfabética- poden aparecer como sublemas outras formas ortográficas posibles, como é o caso, por exemplo, do enunciado de

\footnotetext{
guion o guión. [...] 1. m. Escrito en que breve y ordenadamente se han apuntado algunas ideas o cosas con objeto de que sirva de guía para determinado fin.
}

que atopamos na última edición do DRAE. Dende logo nos dicionarios históricos, ao detectárense ás veces múltiples grafías dunha mesma palabra, é moi frecuente atoparnos con enunciados deste tipo. 
Achámonos neste último caso ante enunciados polimórficos, os cales non só poden informar da existencia de variantes ortográficas, senón moitas veces tamén morfonolóxicas, como sería o caso, por exemplo, dun dicionario que rexistrase como entradas as formas amueblar ou amoblar, carnicería ou carnecería, espabilar ou despabilar, etc. Mesmo -por exemplo, na primeira edición do DUE de María Moliner- dentro dun mesmo enunciado pode aparecer toda unha familia morfolóxica, con remisión á entrada á que se subordinan; é o caso, por exemplo, de

perfección; perfeccionador, -a; perfeccionamiento; perfeccionar; perfeccionarse; perfectamente; perfectibilidad; perfectible; perfectivo, -a. V. bajo "PERFECTO".

Evidentemente, no caso do español, que ten, como o galego, unha ortografía doadamente transcodificable en elementos sonoros, o simple enunciado da entrada en forma escrita proporciona tamén información -aínda que así mesmo indirecta- acerca da pronuncia, ao se poder interpretar como representación desta. Non acontece, en troques, o mesmo con certos extranxeirismos que, como leasing, lead ou pizza, se escriben como na lingua orixinal sen que, por outro lado, exista a correspondencia gráfico-fonética propia do español. Neste caso, como procede o DRAE na súa última edición, tal inequivalencia vén marcada polo tipo de letra -a cursiva- utilizado na lematización, mentres que a pronuncia, cando se dá, se expresa directamente na microestrutura, é dicir, dentro do artigo lexicográfico. Así, por exemplo, considérese no DRAE:

leasing. (Voz ingl.) 1. m. Econ. Arrendamiento con opción de compra del objeto arrendado.

E no DEA:

lead (ing; pronunc corriente, /lid/; pl normal, -s) m En un periódico: Entradilla.

En canto a aspectos relacionados coa pronuncia dados na macroestrutura, cabe engadir que algúns dicionarios -por exemplo, o GDUEA de SGEL- presentan as entradas con separación silábica, dando así información-cremos que innecesaria e ás veces ata discutible-acerca deste particular. Así, des.a.gra.de.ci.do, em.plas.to, ma.nual.men.te.

Agora ben, a información máis estritamente gramatical ofrecida pola forma en que se rexistran as entradas é, evidentemente, a que atinxe ao carácter flexivo, isto é, gramaticalmente variable -ou, pola contra, invariable- das palabras. En primeiro lugar, como é sabido, os substantivos e 
adxectivos que posúen variación de xénero rexístranse na cabeceira do artigo baixo a forma masculina acompañada da terminación feminina, e, no caso dos verbos, que se presentan só nunha forma, o infinitivo, a terminación -ar, -er ou -ir é suficiente para determinar a conxugación -e polo tanto o modelo de flexión- a que corresponde. Só no caso de que se trate dun verbo irregular se fai necesario indicar esa particularidade na microestrutura, remitindo, como fai o DRAE ou o DEA de Manuel Seco, ao modelo de conxugación ou ás formas concretas de carácter irregular. Así, por exemplo, no DRAE:

\section{retraer [...] \ MORF. conjug. actual c. traer.}

\section{A INFORMACIÓN GRAMATICAL NA MICROESTRUCTURA}

É, con todo, na microestrutura onde os dicionarios comúns ofrecen unha maior cantidade de información gramatical, información que, dada dun xeito explícito ou implícito, directo ou indirecto, é sen dúbida superior ao que habitualmente se cre, aínda cando -iso si- presenta deficiencias evidentes, en comparación sobre todo con dicionarios especiais, como os de valencias, de construción e réxime, e os combinatorios ou de colocacións. De feito, no interior dun artigo é posible atopar todo tipo de información gramatical: nel pode darse conta, entre outras cousas, tamén da pronuncia, ortografía, etimoloxía e particularidades de flexión, así como da categorización ou subcategorización da entrada e -o que é máis importante e, polo tanto, ao que aquí vou prestar especial atención- do seu comportamento sintagmático.

\subsection{Indicacións sobre pronuncia, ortografía, etimoloxía e flexión}

Non vou insistir aquí sobre as indicacións - por outro lado evidentes, dado o seu carácter explícito e directo-que aparecen con frecuencia nos dicionarios ao uso sobre a pronuncia, etimoloxía ou propiedades de orde ortográfica ou flexiva. Son indicacións, por certo, que adoitan aparecer no que poderiamos chamar periferia do artigo, é dicir, na parte inicial, despois da entrada, ou final deste, para non se confundiren con ningunha das acepcións en particular. E así é frecuente que a etimoloxía -e o mesmo as particularidades fonético-ortográficas- aparezan, como acontece, por exemplo, no DRAE, inmediatamente despois da entrada, entre parénteses, ou que as particularidades de flexión se indiquen nunha especie de apéndice ao final de artigo. 
Dende logo, como xa sinalou A. Quilis (1982), nun dicionario de español a indicación da pronuncia non ten demasiada xustificación, dada a normal e case exacta correspondencia entre letras e fonemas. A lectura do español (e tamén do galego) non ofrece, efectivamente, ningunha dificultade -sobre todo aos falantes nativos- coñecendo, claro está, esas equivalencias, que, ademais, non son absolutamente idénticas para todos os hispanofalantes (e galegofalantes), o que dificultaría ás veces a súa transcrición fonética'. Só excepcionalmente, no caso de empréstitos tomados doutras linguas na súa orixinal grafía, poden presentarse dificultades neste sentido e, polo tanto, resulta necesario e conveniente realizar algunha observación ao respecto, sempre, naturalmente, que a pronuncia contradiga dalgún xeito as correspondencias letra /son de español ou galego. Considérese, como exemplo, o caso de sándwich tal como aparece na primeira edición do DUE:

sandwich (pronunc. aproximadamente "sanuich"; y a la española, vulgarmente, "sambich"). Pa-

labra inglesa con que se designa [...].

A dificultade deste tipo de indicacións radica, naturalmente, no feito de que o dicionario, ao ir destinado a un público descoñecedor da fonética, non pode utilizar senón os grafemas ordinarios e, polo tanto, dar unha pronuncia tan só aproximada, como acontece no caso anterior. O DEA, penso que acertadamente, dá, non obstante, a transcrición fonolóxica.

Polo que se refire á indicación da etimoloxía, os dicionarios comúns conténtanse normalmente con sinalar, entre parénteses, o étimo precedido da indicación da lingua a que este pertence xunto con, a continuación do étimo, o significado orixinal. Non se engade ningún comentario acerca da evolución fonética e semántica, nin se aborda ningunha discusión de carácter crítico sobre outras posibles hipóteses.

De todas estas informacións a máis destacable é sen dúbida a referente a aspectos flexionais, como é o caso da conxugación dos verbos. Polo xeral, os dicionarios tan só fan referencia aos casos de irregularidade, sinalando as correspondentes formas irregulares ou ben indicando o tipo de conxugación, contida nun apéndice da obra onde se ofrecen os paradigmas prototípicos completos. Este último é, por exemplo, o procedemento seguido polo DEA de Manuel Seco. Máis completo, dende logo, é

1. Resulta, polo tanto, redundante o procedemento seguido polo GDLE, que inclúe invariablemente a pronuncia -segundo a norma española- de todas as súas entradas, as cales aparecen en transcrición fonética: así, ha.ber [aßér] 
o método seguido polo $D R A E$, que na súa versión electrónica ofrece a posibilidade de despregar a conxugación completa de cada verbo, picando simplemente o botón azul que aparece ao lado da entrada. En calquera caso, velaquí un punto máis onde Gramática -no seu sentido máis estrito- e Dicionario interfiren claramente.

\subsection{A marcación gramatical}

Outro caso, por certo, de interferencia que adoita sinalarse á hora de establecer a separación entre Dicionario e Gramática é o representado pola indicación das categorías e subcategorías, habida conta de que estas corresponden de cheo ao terreo gramatical. Teñamos en conta, non obstante, a este respecto que os dicionarios non se ocupan propiamente das categorías gramaticais do mesmo xeito que o fai a Gramática, que as estuda en xeral, como "partes da oración", é dicir, atendendo ao seu comportamento ou funcións dentro da unidade sintáctica por antonomasia. O Dicionario, en cambio, limítase a tomalas como criterio de clasificación das palabras concretas, as cales, de acordo coa devandita clasificación, posuirán un determinado contido categorial, asociado -iso si- a unhas posibilidades combinatorias ou sintácticas.

A categorización nos dicionarios vén dada sempre por marcas, consistentes en abreviaturas, como $a d x$. (adxectivo), adv. (adverbio), $m$. ou $f$. (masculino ou feminino), tr. (transitivo), amb. (ambiguo), etc. Algún dicionario, non obstante, como é o caso do DUE de María Moliner na súa primeira edición (p.XXIII), prescinde desta marcación, habida conta de que a categoría e subcategoría dunha palabra é doadamente deducible da correspondente definición: un substantivo, en efecto, non pode ser definido máis que mediante outro substantivo ou sintagma equivalente, un verbo por medio doutro verbo e así sucesivamente. A falta de categorización nun artigo lexicográfico pode crear problemas, como cando se trata de palabras que poden ser obxecto de recategorización; por exemplo, un adxectivo que pode substantivarse ou funcionar adverbialmente, etc. Por outro lado, nos verbos, non sempre son deducibles da definición os carácteres de transitivo ou intransitivo, etc. De aí que na súa segunda edición o DUE rexistre tamén a categoría ou subcategoría, que de ningún xeito deben tomarse como información redundante, senón absolutamente necesaria.

Como dixen noutro lugar (Porto Dapena 2002a: 253), a indicación da categoría e subcategoría nos dicionarios responde ante todo ao obxectivo fundamental de determinar o comportamento gramatical -tanto paradigmático como sintagmático- das entradas. De todos os xeitos, como 
sinalou recentemente Ignacio Bosque (2006), é certo que os dicionarios deberían incrementar a marcación gramatical, incluíndo subcategorizacións como animado / non animado, contable / non contable nos substantivos, ou, por exemplo, perfectivo / imperfectivo, incoativo / cursivo / terminativo nos verbos, posto que estas características -semanticamente clasemas- tamén inflúen no comportamento morfosintáctico das palabras en cuestión.

Trátase, en todo caso, de trazos que, polo menos nalgunhas ocasións, son dalgún xeito deducibles das respectivas definicións, como penso mostrar nun próximo traballo sobre este tema. Para non me alongar agora demasiado, contentareime con presentar dous ou tres casos: por exemplo, os verbos cuxas definicións están constituídas pola frase verbal facer (esp. hacer) + oración substantiva son verbos factitivos:

acosar. tr. Hacer correr al caballo.

anticipar. $t$ r. Hacer que algo suceda antes del tiempo señalado o esperable, o antes que otra cosa.

Os que, pola súa banda, se definen por empezar, comezar ou poñerse a + infinitivo serán incoativos:

adormecerse. prnl. Empezar a dormirse, o ir poco a poco rindiéndose al sueño.

templar. intr. Dicho de una cosa: Perder el frío, empezar a calentarse.

Terán, pola súa banda, carácter terminativo desinente aqueles que se definen mediante deixar (esp. dejar) de + infinitivo, como

callar. intr. Dicho del mar, del viento, de un volcán, etc.: Dejar de hacer ruido.

morir. intr. Dejar de vivir.

etcétera.

\subsection{A información gramatical nas definicións: o contorno}

Pero falando da definición lexicográfica como fonte de información gramatical, convén non esquecer que esta non consiste -contra o que doadamente se puidese pensar- nunha mera descrición do significado ou contido semántico dunha palabra ou unidade léxica, senón que moitas veces informa tamén, implícita ou explicitamente, acerca do seu comportamento sintagmático. Isto quere dicir que nunha definición poden distinguirse con frecuencia dous elementos: o que propuxen chamar 
enunciado parafrástico, que repite o contido semántico do definido e, polo tanto, en principio, pode substituír a este en calquera contexto, xunto ao que, despois dun memorable traballo de Manuel Seco, deu en denominarse contorno definicional, no que se expresan as condicións contextuais de uso (cfr. Seco 1979; Porto Dapena 1997 e 2002a: 307-328, e Rafel 2006). Así, por poñer un exemplo sinxelo, na definición

comprar. tr. Adquirir algo por dinero

o que aparece subliñado é o contorno, posto que funcionará tamén como complemento directo do definido, fronte ao resto do definiens, que reproduce o contido interno de comprar, pois pode substituír a este, por exemplo, en

Pedro compró una moto $=$ Pedro adquirió por dinero una moto.

Notemos de paso que ás veces a maior parte dos compoñentes dunha definición non analizan -contra o que sería de esperar- o significado do definido, senón que informan máis ben do seu comportamento sintáctico, como é o caso en

confluir. intr. Juntarse dos o más ríos u otras corrientes de agua en un mismo lugar

que vén a ser máis ben unha definición sinonímica, dado que o enunciado parafrástico está representado por unha soa palabra; pero onde se nos informa acerca das características do suxeito (ten que ser unha corrente de auga) e da necesidade dun complemento de lugar.

Non foron estudadas aínda en profundidade as circunstancias en que unha definición ha de ofrecer o seu contorno. Dende logo este non debe faltar, obviamente, cando os elementos que o compoñen teñan que cumprir unhas determinadas condicións semánticas e, polo tanto, exista un condicionamento por parte do definido, representado xeralmente por un verbo ou, se acaso, un adxectivo. Pola contra, non é necesario-e polo tanto non debe aparecer-cando é doadamente deducible do contexto parafrástico. De aí, por exemplo, que esta definición tomada do DRAE:

anglófono. adj. Dicho de una persona o de un país: Que tiene el inglés como lengua nativa

presente un contorno en certo modo redundante, posto que ter unha lingua como nativa tan só pode atribuirse a persoas ou, por metonimia, ao país onde viven. Pero, desgraciadamente, tamén acontece o contrario 
nos dicionarios: ás veces as definicións non son o suficientemente explícitas porque lles falta o contorno, como esta outra, tomada así mesmo do DRAE,

abanicar. $\operatorname{tr}$ Hacer aire con el abanico

onde, evidentemente, falta "a alguien", que é o complemento directo do verbo definido.

De acordo con estas observacións, existen, por unha parte, contornos explícitos e contornos non explícitos, aínda que doadamente deducibles do contexto definicional, como, por exemplo,

sabiondo. adj. coloq. Que presume de sabio sin serlo.

Non fai falta sinalar que se di unicamente de persoas. Por outra ban$\mathrm{da}$, os contornos explícitos poden ser integrados, cando -como é o típicoforman parte do enunciado definicional, e non integrados, se aparecen fóra del; así, en

transcurrir. intr. Dicho generalmente del tiempo: Pasar, correr

o contorno é externo ou non integrado.

Dende logo, o ideal é que o contorno sexa integrado e, ademais, desempeñe no definiens as mesmas funcións sintácticas que ha de desempeñar cando se constrúe co definido, como acontece, por exemplo, nestes casos:

\footnotetext{
contener. tr. Llevar o encerrar dentro de sí una cosa a otra.

trasladar. tr. Llevar a alguien o algo de un lugar a otro.

apto, ta. adj. Idóneo, hábil, a propósito para hacer algo.

digno, na. adj. Merecedor de algo.
}

Non fai falta subliñar, efectivamente, que un contorno deste tipo, ao que chamamos homoxéneo, é altamente informativo dende o punto de vista gramatical, pois non só pon de manifesto o número e características semánticas dos actantes ou valencias, senón tamén as súas respectivas funcións sintácticas.

Lamentablemente, non sempre resulta posible utilizar contornos homoxéneos, e entón bótase man de contornos heteroxéneos, é dicir, aqueles en que nos temos que contentar con explicitar os argumentos ou actan- 
tes do verbo definido, pero con funcións sintácticas distintas ás que lles corresponden cando se constrúen con el.É o caso, entre outros, de

rizar. tr. Formar en el pelo artificialmente anillos o sortijas, bucles, tirabuzones, etc.

onde pelo actúa como complemento circunstancial no definiens, mentres que co definido sería o complento directo; así mesmo, en

resucitar. $t$. Volver la vida a un muerto.

o complemento indirecto sería, non obstante, o directo do definido. Notemos que, nestas circunstancias, o poder informativo -sintacticamente falando- do contorno queda bastante minguado, o que levou a algúns autores de dicionarios -é o caso, por exemplo, do DEA ou do DS e antes, aínda que tan só parcialmente, do DUE- a sinalar por diversos procedementos formais as funcións sintácticas que os elementos do contorno han de desempeñar cando aparecen co definido. Considérese, como exemplo, esta definición do DEA:

retirar. tr. Hacer que [alguien o algo $(c d)$ ] deje de estar [en un lugar (complDE)]

onde, como é sabido, os elementos entre corchetes pertencen ao contorno, os cales, ao desempeñaren funcións sintácticas distintas que co definido, van seguidos da indicación de función entre parénteses.

Como sinalei no seu día nun artigo sobre o contorno (Porto Dapena 1997: 221-222), o poder informativo do dicionario podería potenciarse aínda máis, sinalando na definición, por exemplo, o réxime preposicional, o carácter obrigatorio ou non dun complemento, a súa condición de complemento interno, etc., simplemente utilizando distintos tipos de parénteses: concretamente, propoñía entón usar corchetes ([ ]) para indicar o carácter obrigatorio, parénteses angulares $(\langle\rangle)$ para os complementos non obrigatorios, e, finalmente, parénteses normais para os complementos internos, ademais dunha serie de subíndices encargados de sinalar a función (cando non coincidise coa do definiens) ou o réxime preposicional. Así, resultaría o seguinte:

\footnotetext{
abanicar. tr. Hacer aire ${ }_{\text {od }}[\mathrm{a}$ alguien] (con un abanico u otro objeto a modo de abanico).
}

abastecer. tr. Dar o vender ${ }_{\text {od }}[\text { a alguien }]_{\mathrm{cpde} \text {, con }}<$ todo lo que se necesita $>$. 
Sistema semellante a este, aínda que máis sinxelo, foi o adoptado despois polo $D S$.

De todos os xeitos, habida conta de que toda esta parafernalia de parénteses e subíndices resultan bastante enguedellantes á hora de consultar o dicionario, eu avogaría hoxe por separar nas acepcións os elementos contextuais ou contorno, dos propiamente definicionais ou parafrásticos, rexistrando en primeiro lugar o contexto e logo a definición, que así quedará bastante despoxada de elementos externos. É, por certo, unha práctica que estou a adoptar -penso que con éxito- no meu futuro Diccionario "Coruña" de la lengua española actual (DCLEA) e que, ao meu xuízo, fará deste dicionario, sendo xeral, un dos máis informativos dende o punto de vista sintáctico. Proporei tan só un caso a xeito de simple mostra:

beber $v$. 1. tr. $[\sim$ un animal o persona (suj.) <una cosa líquida $><$ p. e. agua $>$ (od.) $]$. Ingerirla o meterla en la boca haciéndola pasar al tubo digestivo.

Yo nunca bebo soda. Cuando tengo sed, mejor bebo agua. (Santiago, El sueño de América, 21 [CREA])

a) intr. Sin obj. directo puede significar particularmente 'consumir bebidas alcohólicas'. $\vee$ En este caso puede ir acompañado de los advs. de cantidad mucho, demasiado o poco, o también con la expresión como un cosaco. Si no lleva ningún adv., se entiende siempre mucho o demasiado y, por lo tanto, el verbo adquiere más particularmente el significado de 'ser alcohólico o tener el vicio de tomar bebidas alcohólicas'. Finalmente, en frase negativa equivale siempre a 'ser abstemio, no probar el alcohol': "Domingo no bebe, pero su hijo sî".

$\mathrm{Y}$ el español bebe sobre todo fuera de casa y raras veces bebe en solitario. (Domingo, El sabor de España, 40 [CREA])

Vivía en una pensión y bebía como un cosaco. (Leguineche, La tierra, 151 [CREA])

No fuma, no bebe y habla con el desparpajo y la insolencia propias de su edad. (El País [CREA], 02/08/87 [CREA])

b) $[\sim$ alguien (suj.) por algo o alguien (cp.)]. Tomar una copa — p. e. después de un brindis— para celebrar o desear algo positivo a favor de la persona o cosa que se expresa.

Vamos a beber por los buenos consejos. (Loriga, Héroes, 130 [CREA])

Contra sus hábitos, la madre pidió que le sirvieran vino y bebió por su esposo y sus hijos, mencionando cada nombre con tal énfasis (luego comentarían) que quizá quiso despedirse de esta manera. (Otero, Temporada de ángeles, 130 [CREA])

Trátase, como pode verse, da primeira acepción do verbo beber: o contexto aparece entre corchetes, as parénteses angulares serven para indicar a non obrigatoriedade do elemento que acoutan, e nas definicións aparecen só aqueles elementos do contorno (en cursiva) que resultan sintacticamente imprescindibles para facer viable o enunciado definicional. 


\subsection{Información gramatical e separación de acepcións}

No tocante ás informacións gramaticais contidas nas definicións lexicográficas -ou que se poden doadamente deducir delas-, quero referirme agora a unha cuestión que, no que a min se me alcanza, non foi ata agora abordada por ninguén, porque atinxe ao aspecto sen dúbida máis problemático e á vez espiñento da Lexicografía, como é a delimitación ou separación de acepcións. Concretamente, a cuestión que quero formular aquí é ata que punto as acepcións en que se dividen os artigos lexicográficos corresponden -tal como se adoita crer- a significados diversos da palabra-entrada ou, máis ben, a distintos comportamentos sintácticos desta e, polo tanto, proporcionan unicamente información gramatical.

De todos é sabido que, para a separación de acepcións, non existen uns criterios universalmente aceptados polos lexicógrafos, o que explica a gran disparidade con que os dicionarios -agás nos casos, non infrecuentes, de plaxio- describen dende este punto de vista unha mesma palabra, atribuíndolle un maior ou menor número de acepcións, por outra parte non sempre coincidentes. Por regra xeral, confúndense nesta operación características de moi distintas ordes: semánticas, gramaticais, pragmáticas, enciclopédicas... O lexicógrafo, guiado pola súa intuición, limítase a constatar os diversos sentidos que vai detectando nos textos proporcionados polo corpus, sen distinguir normalmente se se trata realmente de significados distintos ou máis ben de puras variantes dun mesmo significado. É o que acontece, como é lóxico, nos dicionarios que, como o $D R A E$, non rexistran máis que acepcións; pero aínda nos que separan acepcións e subacepcions -así no DUE e no DEA-tampouco se seguen uns criterios homoxéneos e, dende logo, obxectivos ${ }^{2}$.

A pregunta que se fan todos os que por primeira vez se teñen que enfrontar coa redacción de artigos é sempre a mesma: que debemos separar en primeiro lugar, os significados ou as construcións? O que en realidade equivale a cuestionar se na separación de acepcións debe primar o sintáctico sobre o semántico ou, pola contra, o semántico sobre o sintáctico.

2. En realidade non existe unha idea clara na lexicografía tradicional acerca do que ha de ser unha acepción e unha subacepción, e, polo tanto, tal distinción obedece así mesmo a criterios meramente subxectivos. Na miña opinión, non obstante, os dous termos deberían empregarse, respectivamente, para referirse aos significados e ás variantes de significado: debe entenderse que dous sentidos dun vocábulo corresponden a significados ou acepcións distintas cando en ambos a devandita palabra forma parte de paradigmas léxico-semánticos diferentes, mentres que, de pertenceren ao mesmo paradigma, acharémonos ante variantes ou subacepcións dun mesmo significado (véxase Porto Dapena (2002a: 199). Sobre os problemas do establecemento de acepcións ocupáronse recentemente J. A. Pascual Rodríguez e R. García Pérez (2007: 117 ess.). 
Dende logo eu non teño ningunha dúbida -como non a tivo tampouco Cuervo no seu $D C R$ - de que a separación de acepcións debe consistir basicamente en distinguir significados ou, por mellor dicir, sentidos, aínda cando cada un destes vaia moitas veces asociado a un determinado comportamento sintáctico. Pero non todo o mundo segue este procedemento: sen ir máis lonxe, o DEA, que representa nestes momentos sen dúbida o mellor dicionario do español actual, parte, como é sabido, dunha separación sintáctica, ao estudar separadamente nos artigos dos verbos as construcións transitiva, intransitiva e pronominal, cousa que o leva, por certo, a repetir en moitos casos o mesmo significado en cada unha desas construcións, duplicando ou triplicando así o número de acepcións. Considérese, por poñer un exemplo sinxelo, o seguinte artigo do DEA:

enfermar A intr 1 Ponerse enfermo [1]. Tb. $(r e g) \operatorname{pr}(\sim \mathrm{se})$. A veces con un compl. DE.

B $\operatorname{tr} 2$ Poner enfermo [1 y 2] [a alguien o algo]. A veces con un compl DE o, raro, CON.

onde se establecen dúas acepcións, que en realidade non son máis que unha, aínda que en construcións sintácticas distintas: as diferenzas veñen aquí dadas pola configuración sintáctica dos actantes, pois o suxeito de 1 é o complemento directo de 2, onde á vez se incrementa un novo actante, un causante ou instigador.

Cando unha mesma acepción dun verbo é susceptible de expresarse mediante construcións distintas o máis frecuente nos dicionarios -porque este é o proceder preferido polo DRAE- é utilizar unha soa definición de acordo cunha desas construcións (a que se considera máis xenuína) e engadir, mediante abreviaturas, na mesma acepción, expresións como "u. t. c. tr. (intr. ou prnl.)", é dicir, "usado tamén como transitivo (intransitivo ou pronominal)". Así,

derrumbar [...].2. tr. Derribar, demoler una construcción o parte de ella. U. t. c. prnl.

A información sintáctica resulta correcta, pero sen dúbida insuficiente, posto que non se explica a modificación funcional de que serán obxecto os actantes.

Estes mesmos dicionarios, non obstante, non seguen un criterio homoxéneo nesta cuestión, posto que, ao lado desta solución, atopamos tamén, o mesmo que no exemplo que acabamos de ver do DEA, unha diversificación de acepcións, que -repito- non presentan máis que unha pura variación na configuración sintáctica dos actantes. Considérese, por exemplo, o seguinte artigo tomado do propio DRAE: 
empapar. 1. tr. Humedecer algo de modo que quede enteramente penetrado de un líquido. Empapar una sopa en vino. U. t. c. prnl. El pan se empapa en el vino. 2. tr. Dicho de una cosa: Absorber dentro de sus poros o huecos algún líquido. La tierra empapa el agua. U. t. c. prnl. La tierra se empapa de agua. 3. tr. Absorber un líquido con un cuerpo esponjoso o poroso. Empapar con un trapo el agua vertida. 4. tr. Dicho de un líquido: Penetrar los poros o huecos de un cuerpo. La llwvia empapa los vestidos. U. t. c. prnl. La lluvia se empapa en la tierra.

cuxas catro acepcións son en realidade unha soa, pero con distintas funcións sintácticas dos mesmos actantes e que poderiamos resumir nas seguintes frases:
1. Juan empapó la esponja en agua.
2. La esponja empapó el agua.
3. Juan empapó el agua con una esponja.
4. El agua empapó la esponja.

onde, como se ve, utilizamos os mesmos argumentos ou actantes, é dicir, $\mathrm{A} 1$ = Juan, A2 = esponja, e A3 = agua (cfr. Porto Dapena 2002b).

\subsection{Información sobre o réxime e as colocacións}

Con ser as definicións, xa sexa, como acabamos de ver, a través dos contornos ou na súa relación con outras acepcións dentro do mesmo artigo lexicográfico, unha importantísima e indiscutible fonte de información gramatical nos dicionarios comúns, non cabe dúbida de que estes, ao mesmo tempo, presentan indubidables deficiencias á hora de precisar o comportamento sintáctico ou combinatorio das palabras. De acordo co que sinalou recentemente Ignacio Bosque (2004: CVII), das definicións de sumo, por exemplo, que tomo do DEA abreviado,

sumo ${ }^{1}$, -ma [...] adj 1. Máximo, o superior a todos los de su especie. 2. Muy grande en calidad o intensidad.

non se deduce -senón máis ben ao contrario- que non sexan aceptables, entre outras, expresións como *Tenía suma hambre ou *Esta lámpara es suma, fronte, en cambio, a Lo haré con sumo gusto, Hay que tener sumo cuidado, que serían perfectamente aceptables. Nos dicionarios, efectivamente, case nunca se precisa con que palabra ou palabras concretas adoita construírse de feito un vocábulo; é dicir, non se rexistra o que hoxe coñecemos co nome de colocacións, así como en moitísimos casos tampouco se mostra o réxime preposicional das 
palabras, segundo acontece, por exemplo, neste artigo, que tomamos do DRAE:

comparar. 1. tr. Fijar la atención en dos o más objetos para descubrir sus relaciones o estimar sus diferencias o semejanza.|| 2. tr. cotejar.

Non se precisa, en efecto, que dos obxectos comparados un deles haberá de actuar como complemento preposicional precedido de con.

Non é, dende logo, agora o momento de entrar na discusión do que debemos entender exactamente por colocación, noción, como se sabe, dabondo controvertida (véxase, entre outros, Alonso Ramos 1994-1995 e Koike 2001) e que eu aplicaría, por razóns prácticas, a toda combinación fixa de palabras -establecida polo uso- que se repite sen que entre elas exista solidariedade nin que, por outro lado, posúa significado idiomático. É dicir, a presenza dunha non esixe necesariamente a da outra -non existe condicionamento ou selección semántica-e, dende o punto de vista do seu contido, cada unha conserva o seu correspondente significado. Así, a expresión frecuente durmir profundamente ou pracidamente será unha colocación, pois nin durmir esixe a profundamente ou pracidamente, nin ningún destes adverbios a durmir, e, ademais, ambas as dúas palabras conservan o seu significado individual. Pero notemos que a semellante combinación non se fai a máis mínima alusión en ningún dicionario xeral da lingua galega (nin da española verbo do comportamento parello de dormir).

En relación, por certo, co español dormir, en todos os dicionarios atopamos rexistradas expresións como dormir a pierna suelta ou dormir como un lirón, que, ao meu modo de ver, seguen sendo tamén colocacións, agora constituídas por dormir e as locucións a pierna suelta e como un lirón. Neste caso penso que tal rexistro se debe á interpretación -sen dúbida errónea- desas combinacións como locucións verbais aínda que, evidentemente, o carácter locucional corresponde unicamente ás correspondentes expresións adverbiais.

Non é este, naturalmente, o único caso en que os dicionarios comúns rexistran colocacións. Obsérvese, por exemplo, o seguinte exemplo tomado do DRAE:

tomar $[\ldots]$ 28. tr. Ponerse a ejecutar la acción o la labor para la cual sirve un determinado instru-

mento. Tomar la pluma, ponerse a escribir. Tomar la aguja, ponerse a coser. 
onde é evidente que tomar la pluma e tomar la aguja son así mesmo colocacións. O rexistro, con todo, deste tipo de construcións é sempre esporádico e, dende logo, nada sistemático.

E outro tanto cabe dicir do réxime preposicional, cando este non é deducible do enunciado definicional, como no caso de comparar, a que me referín antes. Só algúns dicionarios -por exemplo, o DEA e, na maioría dos casos, o DUE- ofrecen realmente esa información. E así, no artigo correspondente á mesma palabra comparar, o DEA di o seguinte:

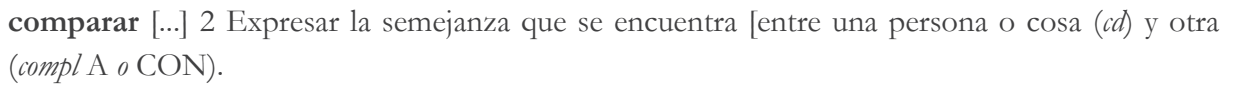

E no DUE de María Moliner:

comparar [...]1 («con») tr. *Examinar alternativamente dos o más cosas para apreciar sus semejanzas y diferencias.

onde, como é sabido e pode aquí observarse, o réxime preposicional se indica mediante unha paréntese diante da definición, aínda que non se precisa que elemento ha de levar a preposición. Son, con todo, sempre casos excepcionais e case sempre esporádicos.

\section{CONCLUSIÓN}

E, xa para concluír, direi que, dende logo, os dicionarios comúns -de tipo xeral e semasiolóxico ou alfabético-, aos que aquí me vin referindo, non informan sobre aspectos morfolóxicos e, sobre todo, sintácticos coa mesma intensidade e detalle con que o fan os dicionarios especializados ou dicionarios gramaticais, é dicir, entre outros, os de valencias, de construción e réxime, combinatorios, de colocacións, etc. Se así non fose, é obvio que a existencia destes últimos carecería de toda xustificación. Non obstante, como creo quedou suficientemente demostrado ao longo desta breve exposición, os dicionarios comúns -aínda sen pretendelo moitas veces-informan sobre eses e outros aspectos en maior medida do que quizais podería pensarse á primeira vista. Isto, por outra banda, non significa que o dicionario se extralimite nas súas funcións de informar sobre o léxico da lingua, entrando nun terreo que non lle corresponde e reservado unicamente á gramática. Realmente, aínda que é verdade que existe certa imbricación entre Dicionario e Gramática, como, por exem- 
plo, acontece -segundo vimos-co tratamento de palabras gramaticais ou formas irregulares de flexión por parte daquel, non é menos certo que os aspectos valenciais e combinatorios en xeral das palabras concretas son aspectos que atinxen só e exclusivamente ao Dicionario, o cal de ningún xeito se pode limitar a informar sobre os significados ou, en xeral, os trazos estritamente paradigmáticos do léxico. En realidade, como moi ben se demostra na análise das definicións lexicográficas, sería imposible delimitar o significado dunha palabra sen ter en conta ao mesmo tempo a súa proxección sintagmática, isto é, o contexto ou contextos en que ese significado pode aparecer; digamos que entre o paradigmático e o sintagmático existe unha interdependencia e, polo tanto, sería imposible o estudo dun prescindindo absolutamente do outro. O único que, en todo caso, cabe lamentar é que os dicionarios comúns non exploten en maior medida as posibilidades que, sen apenas custo, teñen de informar máis e mellor acerca do comportamento morfosintáctico das palabras, como, dende logo, hai que lamentar á vez que os usuarios do dicionario carezan na maior parte dos casos das debidas destrezas como para sacalle todo o rendemento que cabe sacar ás consultas lexicográficas. A verdade é que se usa pouco e mal o dicionario. 